\title{
A QUALITATIVE STUDY OF UNDERGRADUATE ENGINEERING STUDENTS' UNDERSTANDING OF DESIGN A WORK IN PROGRESS
}

\author{
Aleong, R.J., M.A.Sc Candidate; Strong, D.S., Professor \& NSERC Chair in Design Engineering \\ Faculty of Engineering and Applied Science, Queen's University, Ontario, Canada \\ aleongr@appsci.queensu.ca; strongd@ appsci.queensu.ca
}

\section{INTRODUCTION}

The field of engineering education is grounded in research to improve the system of educating engineers. Since engineers design systems, products, and processes for the benefit of society, learning how to design effectively plays a significant role in engineering education. This paper discusses work in progress of research that aims to advance the quality of design education through the application of the science of learning.

\section{PURPOSE OF RESEARCH}

The purpose of this research is to understand students' thinking about design by looking at the meaning students assign to design in the engineering context. By considering the beliefs and values undergraduate engineering students hold towards learning and practicing design, engineering educators can optimize curriculum and learning experiences accordingly.

This research is grounded in phenomenology as the strategy for qualitative inquiry. Phenomenology is concerned with the "meaning, structure, and essence of the lived experience". In this research, learning design is considered as an experience to be explored and understood from the student perspective.

\section{LEARNING THEORY}

The field of educational psychology provides the background in the learning sciences to understand how learning works. In the same way civil engineers apply statics and mechanics to design a bridge, engineering educators should apply the science of learning to design engineering curriculum and enact effective teaching strategies. Therefore, it is the aim of this research to apply the knowledge of how learning works to advance the design of engineering curriculum and teaching. The concepts from the science of learning that are applicable to this research are discussed below.

Transfer of Learning

Transfer of learning, defined as "the effect of prior learning on new learning or performance", is concerned with the ability of a learner to apply what he or she has learned in one context to a new situation. The nature of engineering design is fundamentally a transfer of learning challenge, because it requires students to work with complex, ill-defined problems and apply their knowledge and skills. To aid students in the ability to transfer their learning, it is important to understand students' prior knowledge.

Prior Knowledge

Engineering design involves the interplay of two types of knowledge: declarative and procedural. Declarative knowledge is defined as "the facts and concepts that can be stated or declared" and procedural knowledge involves "knowing how and knowing when to apply various procedures, methods, theories, styles, or approaches" ${ }^{\text {"3 }}$ Prior knowledge plays a significant role in learning because "students connect what they learn to what they already know"3. Prior knowledge also promotes learning when it is activated, sufficient, appropriate, and accurate ${ }^{3}$. In this way, understanding how students think about design will provide insight to engineering educators when teaching and designing curriculum. Motivation and Metacognition

Motivation and metacognition play significant roles in understanding how students think about and approach their learning. While there are several motivational theories that provide insight into one's motivation towards learning, the theory used in this study is the Expectancy-value theory by Eccles and Wigfield ${ }^{4}$. Expectancy-value theory posits that one's motivation to perform a task is influenced by his or her expectancy for success and the value he or she places in the task. The task-value construct is further comprised of four components: attainment value, intrinsic value, utility value, and cost. For the purpose of this study, these task-value components set the basis to understand the meaning students' assign to design in their engineering education.

Metacognition in learning is used to describe the awareness and control of one's cognitive processing ${ }^{2}$. Metacognition is a critical skill for design and is directly linked to the promotion of self-regulation, an attribute of lifelong learning. If engineering educators are to promote metacognitive thinking, an understanding of students' current cognitive awareness is necessary.

\section{RESEARCH ON STUDENTS' ATTITUDES}

This research serves to bridge the research-to-teaching gap by applying the science of learning to influence design education. Several studies point to the importance of understanding students' perceptions of engineering education and the role these perceptions have on engineering recruitment, retention, and performance ${ }^{5}$. The study by Downey and Lucena ${ }^{6}$ investigated "how students understand the distinction between 'science' and 'design"' and found that students hold negative perceptions toward design. The study suggests that curriculum reform to shape students' attitudes is necessary from both an engineering science and design perspective.

There are a number of valid instruments to measure various affective traits of students ${ }^{7}$. However, since these instruments are quantitative in nature and focus on assessment, there is a need for qualitative inquiry that provides detailed description of the underlying factors contributing to the affective results. This approach is evident in the qualitative study by Matusovich, Streveler, and Miller ${ }^{8}$, who use Expectancy-value theory as the framework to measure and describe students' motivational values towards pursuing engineering. From the science of learning and the previous studies on affective traits of engineering students, it is evident that understanding students' attitudes towards learning design will help engineering educators teach design and develop engineering curriculum.

\section{METHODS}

General undergraduate engineering first year students as well as third and fourth year students in select disciplines will be considered for this study. To account for cross-institutional differences, data will be collected at three Canadian institutions with varying engineering student populations: small, medium, and large. Triangulation will be achieved through three sources of data collection: questionnaires, interviews, and institutional curriculum document analysis. Through a "one-shot" questionnaire, students will describe their perceptions and attitudes towards engineering and design. Semi-structured interviews with select students will be conducted to gain a deeper understanding of students' experiences with engineering design. Curriculum document analysis will be conducted to provide insight on the relationship between the engineering curriculum and students' understanding of design. From the students' responses, content analysis will be done to identify categories and themes surrounding their beliefs and values of design education.

\section{DISCUSSION}

This research serves to advance the understanding of undergraduate engineering students' beliefs and values towards learning and practicing design. The results of this research will provide insight for enhancing engineering curriculum and teaching strategies, with direct implications for engineering recruitment and retention. Research ethics approval is underway for data collection to begin in Fall 2011

\section{REFERENCES}

1. Patton M. Qualitative Research and Evaluation Methods. Thousand Oaks, CA: Sage; 2002.

2. Mayer R. Applying the Science of Learning. Boston, MA: Pearson; 2011.

3. Ambrose SA, Bridges MW, DiPietro M, Lovett MC, Norman MK. How Learning Works. San Francisco, CA: Jossey Bass; 2010.

4. Eccles J, Wigfield A. Motivational beliefs, values, and goals. Annu Rev Psychol; 2002;53:109-132

5. Tudor J, Penlington R, McDowell L. Perceptions and their influences on approaches to learning. Eng Ed. 2010;5(2):69-79.

6. Downey G, Lucena J. When students resist: Ethnography of a senior design experience in engineering education. Int J of Eng Ed. 2003;19(1):168-176.

7. Hilpert J, Stump G, Husman J, Kim W, Chung W, Lee J. Steps toward a sound measure of engineering student attitudes: Pittsburgh engineering attitudes scale - revised. Frontiers in Education Conference. San Antonio, TX: ASEE/IEEE; 2009.

8. Matusovich H, Streveler R, Miller R. Why do students choose engineering? A qualitative, longitudinal investigation of students' motivational values. J of Eng Ed. 2010:289-303. 